\title{
Regional consultation on the global health sector strategies on HIV, hepatitis and STIs, 2022-2030
}

Citation: Regional consultation on the global health sector strategies on HIV, hepatitis and STIs, 2022-2030. East Mediterr Health J. 2021;27(9):941-942. https://doi.org/10.26719/2021.27.9.941

Copyright (C) World Health Organization (WHO) 2021. Open Access. Some rights reserved. This work is available under the CC BY-NC-SA 3.0 IGO license (https://creativecommons.org/licenses/by-nc-sa/3.0/igo).

\section{Introduction}

In 2016, the sixty-ninth World Health Assembly adopted three Global Health Sector Strategies (GHSS) on HIV, viral hepatitis and sexually transmitted infections (STIs) for the period 2016-2021 (1). The three strategies were aligned with Universal Health Coverage and the Sustainable Development Goals, and each were framed by a vision to ensure the epidemics would be ended as public health threats by 2030 (1). However, despite considerable progress in some areas of prevention and management, most of the interim targets for 2021 across the three strategies will not be reached. This underscores the need for a revised post-2021 strategic framework to guide the final push to achieve the 2030 goals (2). Therefore, the WHO Regional Office for the Eastern Mediterranean, Cairo, Egypt, held a virtual regional consultation during 24-26 May 2021, which was attended by regional partners and WHO staff from headquarters, regional and country levels (3).

The objectives of the meeting were to:

- inform participants about the GHSS development process, strategic approaches and draft contents;

- discuss the regional implications of the proposed GHSS and related regional considerations; and

- provide regional input to the draft GHSS.

\section{Summary of discussions}

Dr Ahmed Al-Mandhari, WHO Regional Director for the Eastern Mediterranean, emphasized the importance of the new interlinked strategies for strengthening advocacy and guiding interventions towards elimination of the diseases by 2030, and as a step towards the regional goal of "Health for all, by all" (4). He stressed the need to integrate HIV, hepatitis and STI services within broader health systems, with universal health coverage as the way to improve primary health care services, increasing access and providing patient-centred services.

In addition, an overview was provided of the proposed framework, strategic approaches and development process of the new strategies for 2022-2030. The new framework puts people at the centre of the response, highlighting the need to leverage and advance universal health coverage (UHC) and primary health care (PHC) as key strategic directions for HIV, hepatitis and STIs. The strategies focus on the integration and alignment of the disease programmes across different health system domains, including governance, health information, essential health commodities, workforce and financing. Integrated service delivery approaches were emphasized for achieving elimination through decentralization of services, provision of community-led and communitybased services, and adaptation to special settings (for example, prisons, refugee settings and humanitarian crises).

\section{Recommendations}

\section{To WHO}

Advocating for higher political commitment, the allocation of domestic resources and the inclusion of HIV, hepatitis and STI services in UHC essential benefit packages;

- fostering experience-sharing within countries and between WHO regions through convening networks and by documenting and sharing best practices;

- ensuring coordination between WHO headquarters, country and regional offices, so that the necessary technical support is provided to countries;

- providing context-adapted strategic guidance based on epidemiology and addressing key challenges related to complex emergency settings; and

- providing strategic guidance for integrated service delivery for HIV, hepatitis and STIs.

\section{To Member States}

- Identifying areas for integrated service delivery and strengthening inter-programme collaboration and coordination;

- leveraging the PHC system through developing plans for the integration of elements that enable efficiencies and gains for the HIV, hepatitis and STIs responses; and

- adapting services to the needs of the most at-risk and vulnerable groups in a manner that ensures expanded equitable access and leaves no one behind, including key populations, children, women (including pregnant women), migrants, internally displaced populations and refugees.

This summary is extracted from the report on the Regional consultation on the global

health sector strategies (GHSS) on HIV, hepatitis and STIs, 2022-2030, virtual meeting, 24-26 May, 2021 (https://applications.emro.who.int/docs/WHOEMSTD209E-eng. pdf?ua=1). 


\section{References}

1. World Health Organization. Global Health Sector Strategies 2016-2021 (GHSS) Briefing Note. Geneva: World Health Organization; 2015 (https://www.who.int/hiv/strategy2016-2021/GHSS_Briefing_Note_Final_October2015.pdf?ua=1).

2. World Health Organization. Developing global health sector strategies on HIV, viral hepatitis and sexually transmitted infections for 2022-2030. Geneva: World Health Organization; 2021 (https:/www.who.int/news/item/27-05-2021-developing-global-health-sector-strategies-on-hiv-viral-hepatitis-and-sexually-transmitted-infections-for-2022-2030).

3. World Health Organization Regional Office for the Eastern Mediterranean (WHO/EMRO). Regional consultation on the global health sector strategies (GHSS) on HIV, hepatitis and STIs, 2022-2030, virtual meeting, 24-26 May, 2021. Cairo: WHO/EMRO; 2021 (https://applications.emro.who.int/docs/WHOEMSTD209E-eng.pdf?ua=1).

4. World Health Organization Regional Office for the Eastern Mediterranean. (WHO/EMRO). Vision 2023 - Eastern Mediterranean Region. Cairo: WHO/EMRO; 2019 (http://www.emro.who.int/about-who/vision2023/vision-2023.html). 